\title{
Produção de serapilheira na Caatinga da região semi-árida do Rio Grande do Norte, Brasil
}

\author{
Litterfall in the caatinga of the semi-arid region of Rio Grande do Norte, Brazil
}

\author{
José Augusto da Silva Santana ${ }^{1}$, Jacob Silva Souto ${ }^{2}$
}

\section{RESUMO}

O processo de produção de serapilheira e a conseqüente liberação de nutrientes é considerado como um dos mais importantes processos de transferência de energia dentro do ecossistema, e seu conhecimento é necessidade básica para o manejo e conservação de ecossistemas terrestres. Pesquisas com ciclagem de nutrientes na Caatinga são escassas, assim, este trabalho objetivou estudar a dinâmica da deposição de serapilheira pela vegetação da Caatinga da Estação Ecológica do Seridó-RN. O material decíduo foi coletado mensalmente em 30 bandejas durante um ano, sendo seco e separado em folhas, galhos e cascas, material reprodutivo e miscelânea. A Caatinga depositou 2.068,55 $\mathrm{kg} \mathrm{ha}^{-1}$ de material, sendo 79,90\% de folhas; $9,27 \%$ de galhos e cascas; 7,91\% de miscelânea e 2,92\% de material reprodutivo. O pico de deposição da fração material reprodutivo ocorreu em março, enquanto para as demais frações ocorreu em maio, que coincidiu com o início da estação seca durante o período estudado, reduzindo durante o período de menor precipitação (julho-dezembro) e voltando a crescer após as chuvas de janeiro, mostrando marcante sazonalidade.

Palavras-chave: Vegetação, ciclagem de nutrientes, biomassa, deposição foliar.

\begin{abstract}
The production of litter and the consequent liberation of nutrients is considered as one of the most important processes of energy transfer in ecosystems, and its knowledge is basic for the management and conservation of natural and artificial forests. Nutrient cycling research in the Caatinga is scarce; this study analyzes the dynamics of the litterfall in Caatinga shrub-trees at Serido Ecological Station-RN. The deciduous material was collected monthly in 30 wooden litter traps for one year, oven-dried, separated into leaves, bark and branches, reproductive structures and miscellany, and then weighed. After twelve months the Caatinga deposited $2068.55 \mathrm{~kg} \mathrm{ha}^{-1}$ of deciduous material; $79.90 \%$ was leaves, $9.27 \%$ was branches and bark, $7.91 \%$ was miscellany and $2.92 \%$ was reproductive structures. The deposition peak of reproductive material occurred in March, while for the other fractions it happened in May, which coincided with the beginning of the dry season during the studied period. Deposition was reduced during the time of low precipitation (July-December) and increased after the rains of January, showing a marked seasonal pattern. Key words: Vegetation, nutrients cycling, biomass, leaf deposition.
\end{abstract}

\section{Introdução}

A Caatinga é o principal bioma da região Nordeste brasileira, ocupando cerca de $844.453 \mathrm{~km}^{2}$ ou 54,53\% da área da região (IBGE, 2005), possuindo significativa importância sócio-econômica e ecológica. Do ponto de vista climático é caracterizada por um déficit hídrico acentuado, altas taxas de insolação e evapotranspiração, além de reduzida e variável precipitação de ano a ano. Juntamente com os parâmetros climáticos, a vegetação assume papel preponderante na caracterização do bioma.
Aspectos relacionados com o fluxo de deposição de serapilheira, as interações do processo com parâmetros climáticos e edáficos e ciclagem de nutrientes das espécies mais importantes da Caatinga tem sido pouco estudados, apesar da importância do assunto em relação a este tipo de vegetação, principalmente no que se refere às condições físicas do solo, como a melhoria da estrutura, retenção de umidade, aumento da aeração e redução do processo erosivo.

Resultados de estudos sobre ciclagem de nutrientes em florestas antropizadas também permitem inferências sobre as espécies com maior ou menor

1 Departamento de Agropecuária, Centro de Tecnologia, Universidade Federal do Rio Grande do Norte, UFRN, Natal-RN. Brasil. CEP 59.072-970. Caixa Postal 1524. E-mail: augusto@ufrnet.br

2 Centro da Sáude e Tecnologia Rural, Universidade Federal de Campina Grande, UFCG, Patos-PB. Brasil.

E-mail: jacob_souto@yahoo.com.br 
capacidade de reciclagem de nutrientes e seu potencial para recuperação de áreas degradadas. Através destes estudos são disponibilizadas informações sobre a taxa de produtividade e a quantidade de nutrientes que entram naturalmente no sistema soloplanta, o que é de grande significado em atividades de recuperação de áreas degradadas, proteção de fontes hídricas superficiais ou mesmo em projetos de reflorestamento em solos distróficos.

Por ser um fator chave na manutenção dos nutrientes no ecossistema, o processo de deposição da serapilheira, incluindo as taxas anuais de queda do material decíduo e o processo de decomposição desse material, devem ser mais amplamente estudados e conhecidos, especialmente nas condições dos trópicos, onde há grande ocorrência de solos com baixos níveis de nutrientes.

Neste trabalho foram estudados durante 12 meses os ciclos de deposição temporal de diferentes frações da serapilheira da Caatinga arbóreo-arbustiva ocorrente na Estação Ecológica do Seridó.

\section{Material e Métodos}

O estudo foi desenvolvido na Estação Ecológica do Seridó (EsEc-Seridó), localizada no sudoeste do Estado do Rio Grande do Norte, e ocupando área de 1.166,38 ha, no município de Serra Negra do Norte, na Região do Seridó.

Santana et al. (2004) classificaram o clima da EsEc-Seridó, pelo método de Thornthwaite, como DdA'a' tratando-se de semi-árido, com nenhum excesso de água, megatérmico e evapotranspiração real concentrada no período de janeiro a maio, com temperatura média anual de $27,6^{\circ} \mathrm{C}$ e precipitação média anual de $733,7 \mathrm{~mm}$, enquanto a deficiência hídrica alcança $1.697 \mathrm{~mm}$.

No diagrama da distribuição mensal de temperatura do ar e precipitação na EsEc-Seridó (Figura 1), observa-se que a época chuvosa ocorre nos cinco primeiros meses do ano, quando se concentra mais de $87 \%$ da precipitação anual, vindo a seguir uma redução drástica das chuvas, com o mês de junho apresentando redução superior a $82 \%$ em relação ao precipitado em maio.

A temperatura média anual do ar é de $27,6^{\circ} \mathrm{C}$, com a máxima de $29,2{ }^{\circ} \mathrm{C}$ em outubro durante a estação seca, e a mínima de $25,9{ }^{\circ} \mathrm{C}$ nos meses de junho-julho/2003, pouco depois do fim da estação chuvosa. Do mesmo modo, a média anual da umidade relativa do ar é de $63 \%$ apresentando valor máximo de $75 \%$ em abril e mínimo de $55 \%$ em setembro-outubro, enquanto a velocidade média anual do vento alcança $4,0 \mathrm{~m} \cdot \mathrm{s}^{-1}$.

A vegetação da região é classificada como Caatinga arbóreo-arbustiva, hiperxerófila, com características próprias, com sua fisionomia caracterizada por árvores de pequeno porte, freqüentemente com altura inferior a $7 \mathrm{~m}$, apresentando distribuição esparsa e reduzido número de espécies em relação a outros tipos de Caatingas.

As bandejas coletoras foram construídas de madeira, com dimensões de $1 \mathrm{~m}$ x $1 \mathrm{~m}$ x $0,20 \mathrm{~m}$ e fundo em tela de nylon com malha de $1 \mathrm{~mm}$ e situadas a $1 \mathrm{~m}$ de altura do solo. $\mathrm{O}$ material coletado foi seco ao ar durante $48 \mathrm{~h}$, separado nas frações folhas, galhos com diâmetro inferior a $2,0 \mathrm{~cm}$ e cascas, material reprodutivo e miscelânea ou material de

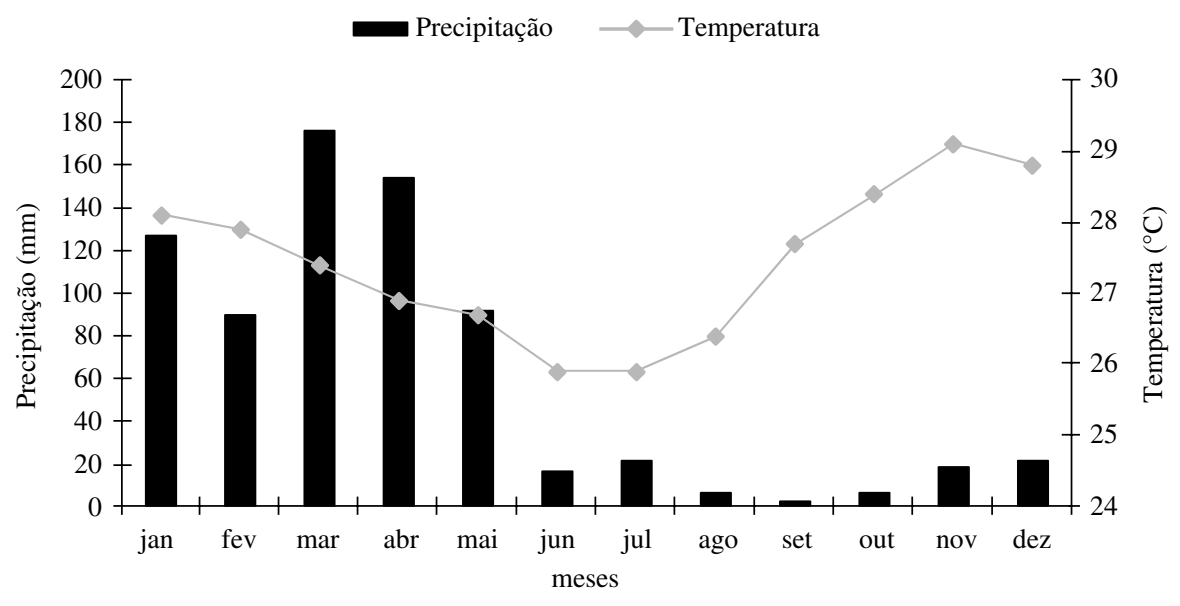

Figura 1. Distribuição mensal de precipitação e temperatura na Estação Ecológica do Seridó, Serra Negra do Norte-RN. 
difícil identificação. Todo o material foi colocado em sacos de papel, identificado por fração, seco em estufa a $65^{\circ} \mathrm{C}$ durante 48 horas e pesado.

\section{Resultados e Discussão}

Após doze meses foram depositados 2.068,55 $\mathrm{kg} \mathrm{ha}^{-1}$ de serapilheira, com as folhas constituindo a fração predominante (Figura 2), responsável por $79,90 \%$ do material decíduo. A fitomassa de galhos e cascas atingiu $9,27 \%$ do total depositado, enquanto a participação de material reprodutivo foi de 2,92\% e a de miscelânea $7,91 \%$.

O valor de deposição total neste trabalho está bem abaixo do estimado por Brown (1980) para florestas tropicais secas, de $5.500 \mathrm{~kg} \mathrm{ha}^{-1} \mathrm{ano}^{-1}$; entretanto se aproxima daquele para florestas subtropicais secas, que atinge $2.780 \mathrm{~kg} \mathrm{ha}^{-1} \mathrm{ano}^{-1}$, dos quais mais de $84 \%$ são folhas. Deve-se observar, porém que os valores citados para florestas tropicais secas foram obtidos através de cálculos interpolados a partir de dados climáticos, podendo ter sido superestimados.

A análise dos resultados de pesquisas sobre a deposição anual de serapilheira em ecossistemas florestais considerados secos indica que, em nível mundial, existe uma grande variabilidade temporal e espacial, com diversos fatores influenciando na deposição do material orgânico, tais como o tipo vegetacional, latitude, altitude, temperatura, fotoperíodo, relevo, disponibilidade de luz durante a estação de crescimento, evapotranspiração, deciduidade, estágio sucessional, herbivoria, disponibilidade hídrica e estoque de nutrientes no solo (Portes et al., 1996), mas principalmente a precipitação pluviométrica e o vento (Diniz \& Pagano, 1997).

De modo geral, a vegetação da Caatinga é fortemente influenciada pelas condições climáticas, especialmente a distribuição da precipitação, a qual se apresenta muito irregular de ano para ano, apesar de apresentar na área estudada um padrão relativamente definido de chuvas nos primeiros meses do ano, seguindo-se depois um longo período de oito meses com forte redução e, às vezes, ausência total de chuvas.

O momento crítico para a vegetação da Caatinga na EsEc-Seridó parece ser o início do período seco, quando todos os parâmetros climáticos que influenciam na quantidade de umidade, como a precipitação, a velocidade do vento e a temperatura, provocam alterações drásticas no ambiente.

A produção mensal de serapilheira total foi ininterrupta durante todo a período de coleta (Tabela 1) mostrando, entretanto, marcante sazonalidade. As maiores taxas ocorreram em maio no início do período seco, quando houve redução drástica da precipitação com as plantas perdendo grande parte de sua biomassa. Foi nesse período que ocorreram os picos de deposição das frações folhas, galhos e cascas, miscelânea e material reprodutivo.

A partir de maio, com a redução na precipitação, a queda de material decíduo continuou paulatinamente até dezembro/2003, porém em quantidades insignificantes a partir de setembro, voltando a aumentar após janeiro de 2004, com o início das chuvas.

Entre agosto e dezembro/2003, período considerado mais seco, com apenas 2,5 $\mathrm{mm}$ de chuva, a

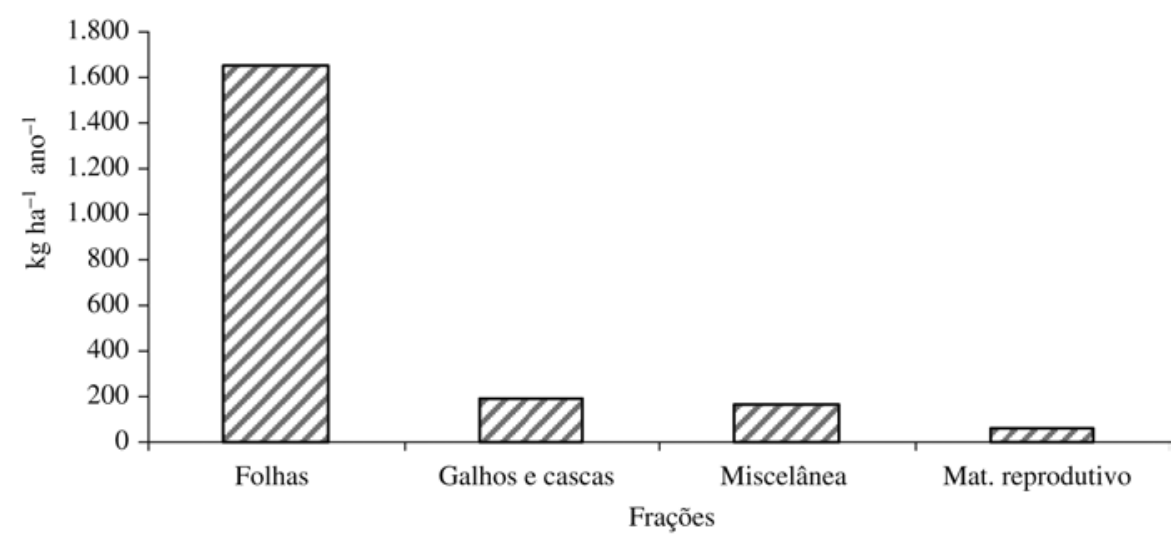

Figura 2. Deposição anual de serapilheira na Caatinga arbóreo-arbustiva na Estação Ecológica do Seridó, Serra Negra do Norte$\mathrm{RN}$, no período de abril/2003 a março/2004. 
Tabela 1. Produção mensal e total de serapilheira e erro padrão da média (epm) na Estação Ecológica do Seridó, Serra Negra do Norte-RN, no período de abril/2003 a março/2004.

\begin{tabular}{|c|c|c|c|c|c|}
\hline Meses & Folhas & Galhos e cascas & Miscelânea & Mat. reprodutivo & Total \\
\hline abril & 180,12 & 20,18 & 9,52 & 32,77 & 242,59 \\
\hline maio & 592,56 & 29,46 & 14,56 & 61,23 & 697,81 \\
\hline junho & 371,53 & 18,43 & 5,19 & 13,15 & 408,30 \\
\hline julho & 149,66 & 9,67 & 0,56 & 3,20 & 163,09 \\
\hline agosto & 165,21 & 10,04 & 0,16 & 0,99 & 176,40 \\
\hline setembro & 29,34 & 12,00 & 0,53 & 0,53 & 42,40 \\
\hline outubro & 6,27 & 9,16 & 0,74 & 0,52 & 16,69 \\
\hline novembro & 2,73 & 5,67 & 0,49 & 0,63 & 9,52 \\
\hline dezembro & 1,83 & 6,25 & 0,84 & 0,68 & 9,60 \\
\hline janeiro & 11,88 & 21,39 & 0,58 & 4,84 & 38,69 \\
\hline fevereiro & 52,06 & 22,72 & 9,25 & 12,90 & 96,93 \\
\hline março & 89,54 & 26,86 & 17,93 & 32,20 & 166,53 \\
\hline TOTAL & 1652,77 & 191,83 & 60,35 & 163,64 & 2068,55 \\
\hline epm & 51,89 & 2,36 & 1,82 & 5,51 & 58,69 \\
\hline
\end{tabular}

produção de serapilheira total foi de apenas 254,61 $\mathrm{kg} \mathrm{ha}^{-1}$, sendo que deste total mais de $46 \%$ foram devidos à intensa queda de folhas de $A$. pyrifolium em agosto, indicando que o seu pico de deciduidade foliar ocorreu quatro meses após o início da estação seca.

A variabilidade de queda da serapilheira durante o ano foi elevada, atingindo apenas $9,52 \mathrm{~kg} \mathrm{ha}^{-1}$ no pico do período seco em novembro, quando choveu apenas $0,5 \mathrm{~mm}$, e o máximo em maio, início da estação seca, com $697,81 \mathrm{~kg} \mathrm{ha}^{-1}$, evidenciando assim a relação entre umidade e produção de serapilheira.

Deve-se observar que os solos da área apresentam textura arenosa e são rasos e pedregosos, com baixa capacidade de retenção hídrica, sendo assim um ambiente de restritivas condições de umidade no período seco, já que se torna mais difícil para as plantas absorverem água porque aumenta a força de retenção e diminui a disponibilidade de água no solo.

Em condições de forte déficit hídrico as espécies da Caatinga utilizam suas adaptações morfológicas e/ou fisiológicas que possibilitam a sobrevivência em condições de seca, como a senescência e a caducifolia, depositando então grandes quantidades de material decíduo para reduzir a transpiração (Silva et al., 2004).

O padrão de maior deposição de serapilheira logo após a estação chuvosa foi observado também por Froufe (1999), o qual credita o evento ao agravamento do estresse hídrico, ocasionando a queda de folhas como medida preventiva à alta perda de água por transpiração durante o período seco seguinte.

Vogt et al. (1986) sintetizando e analisando dados disponíveis sobre a produção e acúmulo de matéria orgânica, citam que várias tentativas foram feitas para correlacionar a produção de serapilheira com os dados de precipitação porém nenhuma obteve sucesso.

É provável que a produção de serapilheira na Caatinga estudada não esteja apenas diretamente relacionada com os fatores climáticos analisados, mas também ao comportamento perene ou decíduo das espécies e a proporção desses grupos na população, conforme observado também por Vogt et al. (1986).

Sabe-se que a caducifolia é resultante de uma série de processos metabólicos, ligados à fisiologia de cada espécie e também dos estímulos vindos do ambiente tais como: fotoperíodo, estresse hídrico, fertilidade do solo, variáveis climáticas etc. No caso da Caatinga estudada, a redução acentuada da precipitação parece ser o fator abiótico que desencadeia o processo de senescência, reduzindo assim a superfície foliar dos indivíduos da população e, conseqüentemente, reduzindo a perda de água do sistema.

Nos trabalhos consultados sobre produção de serapilheira, independente do bioma estudado, a fração folha normalmente constitui a maior proporção dos resíduos orgânicos que caem ao solo, sendo por isso mesmo a fração mais estudada. Assim, a curva de deposição mensal da fração é 
muito semelhante a da serapilheira total, como também foi observado na vegetação da Caatinga arbóreo-arbustiva da EsEc-Seridó.

Neste trabalho, a produção de serapilheira foliar atingiu cerca de $1.652,77 \mathrm{~kg} \mathrm{ha}^{-1}$ ano, o que corresponde a $79,90 \%$ de todo o material decíduo. No levantamento que realizaram em nível mundial, enfocando a quantidade de detritos orgânicos depositados por diferentes tipos de vegetação, Bray \& Gorham (1964) concluíram que, nas diferentes zonas ecológicas consideradas, a participação das folhas situou-se entre $58 \%$ e $79 \%$ do material decíduo. Portanto, a Caatinga estudada se situou pouco acima da faixa superior de deposição foliar considerada pelos autores citados acima, que, entretanto não se referiram as florestas tropicais secas.

Os resultados dos poucos estudos desenvolvidos na Caatinga quantificando a produção de serapilheira foliar apresentam percentuais muito inferiores aos obtidos neste trabalho, com Dantas (2003) obtendo menos de $40 \%$ do total para esta fração. Para outros ecossistemas secos, Brown (1980) citou que cerca de $91 \%$ da serapilheira total eram folhas, enquanto Martínez-Yrízar \& Sarukhán (1990) obtiveram cerca de $70 \%$ de folhas na serapilheira de uma floresta decídua mexicana.

$\mathrm{Na}$ Caatinga, a produção de serapilheira foliar parece estar ligada a dois fatores altamente relacionados, que são o início do período seco na área, com redução do teor de umidade no solo, e o caráter caducifólio das espécies, com conseqüente e imediata abscisão das folhas para reduzir as perdas de água por transpiração. Assim, como algumas espécies da Caatinga mantém parte das suas folhas durante o ano, mesmo com deficiência hídrica, é provável que o pico de deposição de biomassa foliar decídua logo no início do período seco, seja resultado da perda de folhas das espécies caducifólias, vindo a seguir vários meses com taxas reduzidas de deposição, proporcionadas principalmente pela contribuição das espécies perenifólias, até o início de nova estação chuvosa, quando as espécies caducifólias recuperam suas folhas.

Na Caatinga de Serra Talhada (PE) Machado et al. (1997) verificaram que a deposição de folhas foi ininterrupta durante o ano, mas como esperado, a queda de folhas tornou-se mais acentuada após a estação chuvosa, semelhante ao que se observou na Caatinga da EsEc-Seridó, mostrando assim um certo padrão temporal de produção de serapilheira no bioma Caatinga. Desse modo, o padrão de deposição da Caatinga na EsEc-Seridó parece ser dependente do estresse hídrico e também, da proporção entre espécies caducifólias e perenifólias na área. Entretanto, dependendo do grau de umidade no solo, as árvores podem permanecer ainda com significativa quantidade de folhas, mesmo sendo caducifólias, como se observou em vários indivíduos de Caesalpinia pyramidalis, Piptadenia stipulacea, Croton sonderianus e Aspidosperma pyrifolium, mesmo no período mais seco do estudo.

Barbosa et al. (2003) comentam que as espécies decíduas são predominantes nas regiões áridas e semi-áridas variando o grau de deciduidade de acordo com a reação aos déficits hídricos, uma vez que há espécies que perdem as folhas logo no final da estação chuvosa e outras que as mantém até o final da estação seca, criando, portanto mosaicos temporais e espaciais dentro de microambientes durante a estação seca. Assim, o padrão de deciduidade das espécies parece ser principalmente afetado pela precipitação e pelo tempo de duração do período seco, com a umidade do solo sendo o fator preponderante no desencadeamento do processo em florestas secas.

Os resultados obtidos na EsEc-Seridó apresentam semelhança com aqueles observados por Barbosa et al. (2003) sobre a fenologia de 28 espécies lenhosas da Caatinga em Sousa (PB) e Serra Talhada (PE). Os autores concluíram que 23 espécies eram decíduas, perdendo as folhas de maneira concentrada na estação seca, sendo que 9 destas perdiam as folhas logo no final da estação chuvosa (maio) e 14 no final da estação seca (outubro a dezembro), incluindo no primeiro grupo Aspidosperma pyrifolium, Bauhinia cheilanta, Caesalpinia ferrea e Caesalpinia pyramidalis, enquanto no segundo ocorriam Croton sonderianus, Combretum leprosum, Jatropha mollissima, Piptadenia stipulaceae e Amburana cearensis, espécies que respondem por mais de $80 \%$ da densidade nas parcelas estudadas na EsEc-Seridó.

A fração galhos e cascas foi o componente da serapilheira que apresentou a segunda maior produção após as folhas, depositando $191,75 \mathrm{~kg} \mathrm{ha}^{-1} \mathrm{ano}^{-1} \mathrm{o}$ que corresponde a 9,27\% do total, com um pico de deposição entre janeiro e junho, coincidindo com o período chuvoso e início do período seco.

Neste trabalho não se verificou nenhum material com diâmetro superior a $2,0 \mathrm{~cm}$, o que significa que o material lenhoso coletado eram galhos finos, cascas e partes de galhos grossos que se desprendiam das 
árvores. Assim, observou-se que mesmo quando mortas, as árvores permaneciam de pé, liberando lentamente pequenos fragmentos, mas nunca galhos grossos. A contribuição das cascas das árvores para esta fração foi significativa, principalmente pela presença de espécies que perdem suas cascas durante grande parte do ano como Cnidoscolus phyllacanthus, Jatropha mollissima, Amburana cearensis e Anadenanthera macrocarpa.

Os valores em nível mundial para galhos e cascas, mesmo em florestas secas, mostram grande variabilidade, a exemplo dos estudos de MartínezYrízar \& Sarukhán (1990) que obtiveram 17\% em floresta decídua no México. Já em outras florestas, como na estacional semidecídua montana, Dias \& Oliveira Filho (1997) quantificaram em $2.010 \mathrm{~kg}$ $\mathrm{ha}^{-1}$ ano $^{-1}$ a participação da fração lenhosa, com um padrão de deposição mais confuso, com pequena tendência de aumento nos meses de maior precipitação, possivelmente em função da ação mecânica das chuvas e do vento sobre o dossel, mostrando porém certa aleatoriedade.

Em floresta estacional decidual König et al. (2002) observaram que a grande variabilidade da queda de galhos foi em decorrência de fenômenos climáticos adversos, como tempestades com ventos anormais, e também pelo fato do menor tamanho das bandejas, possivelmente não adaptadas para a coleta da fração. Os autores verificaram também correlação negativa com a precipitação e a temperatura do ar. Em uma floresta mista em Hong Kong, Lam \& Dudgeon (1985) correlacionaram a produção do material lenhoso com a temperatura e o estresse hídrico, que podem ser importantes fatores que influenciam na morte de galhos, o que, no entanto, requer um período de dois a quatro meses para manifestar seus efeitos. Por seu turno, Vogt et al. (1986) comentam que, exceto para a temperatura mínima, nenhuma das outras variáveis climáticas, isoladas ou combinadas, explicaram qualquer variação na produção de galhos e cascas tanto para florestas de coníferas como de folhas largas.

Na EsEc-Seridó foi observado redução na produção desta fração a medida que as chuvas também se reduziam, com os menores picos de produção ocorrendo em novembro-dezembro, quando choveu apenas $0,5 \mathrm{~mm}$ na área. Entretanto, com o início das chuvas em janeiro, houve um substancial aumento na produção da fração, o que pode estar relacionado ao efeito mecânico da chuva no processo de deciduidade dos ramos ressequidos durante a época seca anterior. Desse modo, é provável que o pico de produção ocorrido em abril-junho/2003 seja resultado da mortalidade causada pela seca ocorrente ainda no ano anterior, quando choveu apenas 2,2 mm entre os meses de agosto a dezembro.

A fração material reprodutivo, que incluiu botões florais, flores, frutos e sementes foi responsável por $2,92 \%$ da produção total de serapilheira, o que corresponde a $60,41 \mathrm{~kg} \mathrm{ha}^{-1}$ ano $^{-1}$. Poucos trabalhos quantificam essa fração, e os valores aqui apresentados evidenciam a necessidade de se monitorar, também, o comportamento fenológico das espécies durante a fase das coletas, com o objetivo de coletar dados que possam ajudar a explicar alguns resultados aparentemente contraditórios, e mesmo determinar a influência isolada de cada espécie para determinado evento ocorrido no processo de deposição.

Como as demais frações, esta seguiu o mesmo padrão das chuvas ao longo do período de coleta, apresentando um pico que tem início no meio do período chuvoso e se prolonga até o seu final, reduzindo drasticamente a partir de julho, quando praticamente deixou de chover na área.

A menor produção ocorreu entre julho/2003 a janeiro/2004, abrangendo assim quase todos os meses mais secos de 2003. Nesse período, a produção foi de apenas $3,9 \mathrm{~kg} \mathrm{ha}^{-1}$ ou $6,45 \%$ do total observado para a fração, com a média mensal sendo pouco superior a $0,55 \mathrm{~kg} \mathrm{ha}^{-1}$, evidenciando a sazonalidade da queda da fração.

Assim, a quase totalidade do ciclo de floração, frutificação e queda desse material na Caatinga da EsEc-Seridó ocorre logo após o início do período chuvoso, se estendendo pouco além do final das chuvas, ocorrendo entretanto simultaneidade entre as fenofases de floração e frutificação. Desse modo, o efeito da precipitação na produção desta fração foi relevante para algumas espécies ocorrentes na EsEc-Seridó. Observações de campo mostram que em março, vários indivíduos adultos de Tabebuia impetiginosa estavam em rápido processo de perda de folhas e floresceram logo em seguida, enquanto que em fevereiro, no meio da estação chuvosa, foram coletadas grandes quantidades de flores de Croton moritibensis, Croton sonderianus e Commiphora leptophloeos.

A produção desta fração normalmente tem sido correlacionada com a precipitação, como notaram Diniz \& Pagano (1997) em condições de floresta mesófila semidecídua na região de Araras-SP, onde 
a participação das flores foi de $15 \mathrm{~kg} \mathrm{ha}^{-1} \mathrm{ano}^{-1}$, com as maiores produções ocorrendo em julho e agosto (inverno), e afirmaram ainda que esse valor pode ser creditado as Compositae que florescem nessa época do ano.

César (1993) observou, também no período seco, quantidades mínimas de material reprodutivo nas bandejas, entretanto comenta que diversos autores têm relatado o aumento da floração a partir da transição entre a estação seca e o início da chuvosa para as regiões tropicais e subtropicais, mas este padrão não se observou na Caatinga.

A fração miscelânea contribuiu com 163,64 kg $\mathrm{ha}^{-1}$ ano $^{-1}$ o que corresponde a 7,91\% da serapilheira total, apresentando um longo período de produção que se estende de janeiro a junho, com um pico em maio, e reduzida deposição no período mais seco das coletas (agosto-dezembro/2003), semelhante ao observado para a fração material reprodutivo.

Em grande parte dos trabalhos relativos à produção de serapilheira, a fração miscelânea é composta de fragmentos de folhas, galhos, ramos, flores, frutos, sementes e outros materiais vegetais de difícil identificação, além de insetos ou partes destes e fezes, apresentando desse modo grande variabilidade na sua composição e no seu padrão de deposição.

Neste trabalho, esta fração foi composta em grande parte por penas de pássaros e corpos e fezes de Cephalocoema sp. (falso bicho-pau), inseto da ordem Phasmatodea, muito comum na Caatinga local e que se alimenta de folhas de espécies como Combretum leprosum, Aspidosperma pyrifolium, Croton sonderianus e Croton moritibensis, preferencialmente.

A grande redução na produção da fração no período seco, certamente foi reflexo da diminuição da precipitação na área, reduzindo também a qualidade e a quantidade de matéria verde em condições de ser consumida pela população de insetos, tanto é que de agosto a dezembro, período seco na região, não foram coletados insetos ou fezes, o que só voltou a acontecer em janeiro/2004, com o reinício das chuvas.

Em quatro ambientes semi-áridos da Venezuela, Poulin et al. (1992) observaram que a abundância de artrópodes seguiu o mesmo padrão observado na EsEc-Seridó, com a população sendo maior na estação úmida e a abundância mostrando relação positiva com a precipitação.

Evidenciando a participação dos insetos herbívoros no processo de deposição de serapilheira, Martínez-Yrízar \& Sarukhán (1990) observaram que as fezes de invertebrados foram uma importante fração dos restos fragmentados durante a estação chuvosa, indicando um aumento nas atividades de insetos neste período, com posterior queda de produção na estação seca. Do mesmo modo, em uma floresta mista em Hong Kong, Lam \& Dudgeon (1985) citaram que o nível de ataque de herbívoros reduziu acentuadamente com o aumento na queda de folhas na estação seca.

Os resultados obtidos neste estudo são semelhantes aos obtidos por Dias \& Oliveira Filho (1997), os quais quantificaram a fração miscelânea em $80 \mathrm{~kg} \mathrm{ha}^{-1} \mathrm{ano}^{-1}$ e composta predominantemente por fezes, além de restos de invertebrados, como membros e exoesqueletos de artrópodes.

\section{Conclusões}

A deposição mostrou-se fortemente sazonal e ininterrupta durante o ano, com a maior produção ocorrendo no início da estação seca e a menor nos meses finais da mesma estação;

A elevada produção de material decíduo no início da estação seca, provavelmente é resultado do mecanismo de adaptação das espécies do bioma para reduzir a perda de água no período seco via transpiração;

A fração foliar foi o principal constituinte da serapilheira total, com Caesalpinia pyramidalis depositando significativa quantidade de material, o que pode estar relacionado com a elevada dominância da espécie na área;

A fração galhos e cascas foi contínua durante o estudo, sendo a segunda maior produtora de serapilheira e apresentando longo pico de no período chuvoso;

A fração miscelânea foi basicamente de origem animal, apresentando grande deposição entre fevereiro e junho, época de renovação foliar na Caatinga, com presença preponderante de corpos e fezes de Cephalocoema sp. (falso bicho-pau). 


\section{Referências Citadas}

Barbosa, D.C.A.; Barbosa, M.C.A.; Lima, L.C.M.

2003 Fenologia de espécies lenhosa da Caatinga. In: Leal, I.R.; Tabarelli, M.; Silva, J.M.C. (Eds.) Ecologia e conservação da Caatinga. Recife: Editora Universitária da UFPE. pp. 657-694.

Bray, J.R.; Gorham, F.

1964 Litter production in forests of the world. Advances in Ecological Research (2): 101-157.

Brown, S.

1980 Rates of organic matter accumulation and litter production in tropical forest ecossystems. In: Carbon dioxide effects research and assessment program: the role of tropical forest on the world carbon cycle. Gainesville: Center for Wetlands. pp. 118-139.

César, O.

1993 Produção de serapilheira na mata mesófila semidecídua da Fazenda Barreiro Rico, município de Anhembi, SP. Revista Brasileira de Biologia, 53 (4): 671-681.

Dantas, J.S.

2003 Dinâmica da produção e decomposição de folhedo e ciclagem de nutrientes em um ecossistema de Caatinga arbórea no agreste da Paraíba. Monografia (Graduação). Universidade Federal da Paraíba, Areia-PB. 32 p.

Dias, H.C.T.; Oliveira Filho, A.T.

1997 Variação temporal e espacial da produção de serapilheira em uma área de floresta estacional semidecídua montana em Lavras-MG. Revista Árvore, Viçosa 21 (1): 11-26.

Diniz, S.; Pagano, S.N.

1997. Dinâmica de folhedo em Floresta Mesófila Semidecídua no Município de Araras, SP. I-Produção, Decomposição e Acúmulo. Revista do Instituto Florestal, São Paulo. 9(1): 27-36.

Froufe, L.C.M.

1999 Decomposição de serapilheira e aporte de nutrientes em plantios puros e consorciados de Eucalyptus grandis Maiden, Pseudosamanea guachapele Dugand e Acácia mangium Willd. Dissertação (Mestrado). Universidade Federal Rural do Rio de Janeiro, Seropédica-RJ. $73 \mathrm{p}$.
IBGE

2005 Mapa de Biomas e de Vegetação. Instituto Brasileiro de Geografia e Estatística. Rio de Janeiro. Disponível em: http://www.ibge.gov.br Acesso em 29 de agosto de 2005.

König, F.G.; Schumacher, M.V.; Brun, E.J.; Seling, I.

2002 Avaliação da sazonalidade da produção de serapilheira numa floresta estacional decidual no município de Santa Maria-RS. Revista Árvore, 26 (4): 429-435.

Lam, P.S.; Dudgeon, D.

1985 Seasonal effects on literfall in a Hong Kong mixed forest. Journal of Tropical Ecology, 1 (1): 55-64.

Machado, I.C.S.; Barros, L.M.; Sampaio, E.V.S.B.

1997 Phenology of Caatinga species at Serra Talhada, PE, Northeastern Brazil. Biotropica, 29 (1): 57-68.

Martínez-Yrízar, A.; Sarukhán, J.

1990 Litterfall patterns in a tropical deciduous forest in Mexico over a five-year period. Journal of Tropical Ecology. 6 (4): 433-444.

Portes, M.C.G.; Koehler, A.; Galvão, F.

1996 Variação sazonal da deposição de serapilheira em uma Floresta Ombrófila Densa Altomontana no Morro do Anhangava-PR. Floresta, 26 (1/2): 3-10.

Poulin, B.; Lefebvre, G.; McNeil, R.

1992 Tropical avian phenology in relation to abundance and exploitation of food resources. Ecology, 73(6): 2295-2309.

Santana, J.A.S.; Santana Júnior, J.A.S.; Souto, J.S.; Macêdo, A.B. 2004 Balanço hídrico e classificação climática de Thornthwaite da Estação Ecológica do Seridó, Serra Negra do Norte-RN. Brasil Florestal, 23 (80): 9-16.

Silva, E.C.; Nogueira, R.J.M.C.; Azevedo Neto, A.D.; Brito, J.Z.; Cabral, E.L.

2004 Aspectos ecofisiológicos de dez espécies em uma área de Caatinga no município de Cabaceiras, Paraíba, Brasil. Iheringia, Série Botânica, 59 (2): 201-205.

Vogt, K.A.; Grier, C.C.; Vogt, D.C.

1986 Production, turnover and nutrient dynamics of above and belowground detritus of world forests. Advances in Ecological Research, 15: 203-234. 